\title{
Transitional carcinoma of the upper urinary tract: a histological and cytopathological study
}

\author{
WILMA J HIGHMAN \\ From the Department of Pathology, St Peter's Hospitals and Institute of Urology, London
}

SUMMARY A histological and cytopathological study of 54 patients with transitional carcinoma of the upper urinary tract was undertaken. There were 17 patients with grade 1 tumours, 35 with grades 2 or 3 , and two with carcinoma in situ. Only 16 had non-invasive tumours. A preoperative cytological diagnosis of tumour was made in $67 \%$ of the group as a whole and in $75 \%$ of patients with grade 2 or 3 tumours. Seventy per cent of voided urines and $80 \%$ of ileal conduit urines were positive for tumour. Cytological grading correlated with histology in 12 of 14 grade 1 tumours and 26 of 35 grade 2 or 3 tumours, with seven assigned grade 1 . Two cases of pelvicalycine carcinoma in situ were graded 3 by cytology. Cytological investigation by those experienced in urinary cytology has an important diagnostic contribution to make in transitional carcinoma of the upper urinary tract.

The use of urine cytology in the diagnosis of transitional carcinoma of the bladder has been well documented. ${ }^{2}$ There is less information on the application of urine cytology to the diagnosis of tumours of the pelvicalycine system or ureter. Early diagnosis and treatment of these tumours is essential as invasion of the deeper tissues, in particular the renal parenchyma, is of grave prognostic importance. As tumours of the upper urinary tract can present serious diagnostic difficulties for both clinician and radiologist, a cytological diagnosis of tumour can be invaluable in the clinical treatment of any such patient. A cytological diagnosis must, however, be reliable with no false positives, as treatment is liable to entail major surgery. Recent developments have facilitated localised surgical resection of well differentiated upper tract tumours in accessible sites. ${ }^{3}$ A cytological diagnosis of tumour, together with an assessment of tumour grade in the cytological material, may, therefore, be of considerable value to the surgeon in planning the operative management. This paper reports on the histological and cytopathological features in a series of 54 patients with transitional carcinoma of the upper urinary tract from whom material was sent for cytological diagnosis before surgery. None of these patients had coincidental tumours of the bladder or urethra at the time of surgery.

Accepted for publication 28 November 1985

\section{Material and methods}

CLINICAL MATERIAL

Of the 54 patients, 42 were men and 12 women. They were aged 33-80 years: 35 patients were in the 50-70 age group. There was a history of recurrent transitional carcinoma of the bladder in 21 patients, of whom eight had had total cystectomy or cystoprostatectomy. In five of these upper tract tumours developed within four years and in the remainder between six and eight years after cystectomy. Eleven patients in this group developed a second upper tract tumour (nine within two years and two within four years of the first tumour). In one patient a second tumour was found in the opposite renal pelvis within two months of the first. Three patients had multiple recurrences all of which were bilateral and affected successively the pelvicalycine systems of both kidneys, ureters, and ileal loops.

SURGICAL MATERIAL

There were: 31 nephroureterectomy specimens; four partial nephrectomies; eight localised resections of tumours; and 11 segments of ureter. Multiple sections were taken for histological examination from the tumours, the surrounding urothelium, and the distal ends of resection.

\section{CYTOLOGICAL MATERIAL}

This comprised the following:

1 Voided urine: one, and where possible, three specimens of fresh pre-instrumentation urine. 
2 Ileal conduit urine freshly passed into an empty bag.

3 Ureteric and pelvic urine collected during cystoscopy and retrograde pyelography.

4 Urine aspirated from the pelvicalycine system during antegrade pyelography.

5 Brushings of suspicious areas in the ureter or pelvis. These were made with a nylon bristle brush, which was cut off and immersed in $95 \%$ ethyl alcohol.

6 Aspirates from intrarenal or perirenal masses. Smears were made on glass slides and immediately fixed in $95 \%$ ethyl alcohol. The syringe and needle were washed out with saline and the washings submitted with the smears. Any tissue fragment or blood clot was fixed in $10 \%$ formol saline and sent for histological section.

One fifth volume of $95 \%$ alcohol was added to all urine specimens to act as a preservative during transportation. Millepore filter preparations (pore size 5, Millepore UK) were made from all urines, washings, and brushing fluid. Additional smears were made from thick or heavily blood stained material. Papanicolaou stain was used on all cytological material and haematoxylin and eosin on sectioned clot or tissue.

\section{Results}

\section{HISTOPATHOLOGY}

The tumours were located in the pelvicalycine system in 39 patients, two of whom had associated ureteric tumours, and in the ureter in 15 . Two of these were ureteric stump tumours in patients with previous nephrectomy for transitional carcinoma. Tumours were localised in only 10 patients. In 44 they were multifocal or extensive. One patient had multiple renal calculi. The tumours were graded histologically using the WHO system: grade 1 differentiated; grade 2 intermediate; grade 3 poorly differentiated. Table 1 shows the results of the histological grade and pattern

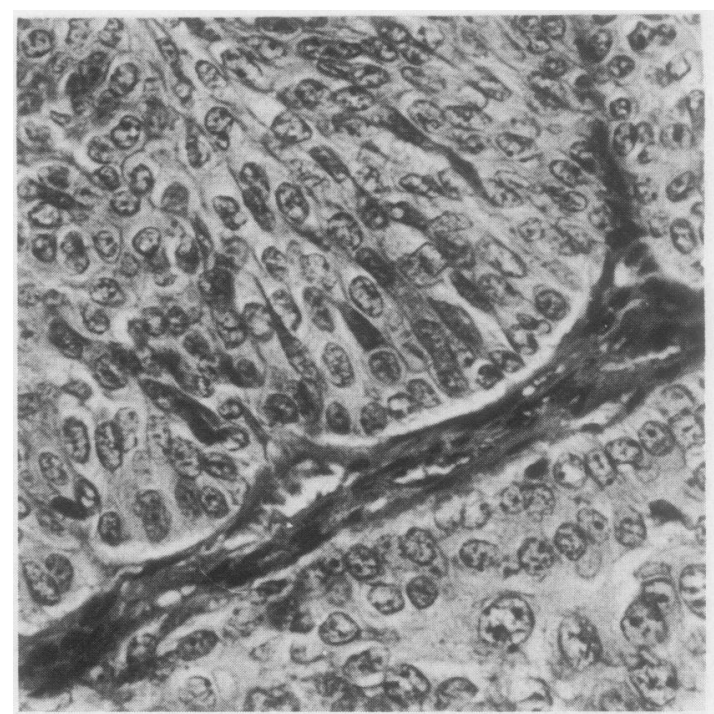

Fig. 1 Section of transitional carcinoma: mixed grades 1 and 2. (Haematoxylin and eosin.) $\times 400$.

of invasion for each grade of tumour.

The tumour grade was essentially uniform in 41 patients. There were 17 with grade 1 tumours, 19 with grade 2, and three with grade 3 tumours. Tumour differentiation was not uniform in 13 patients, and areas of higher grade were present alongside better differentiated areas (Fig. 1). The less well differentiated areas were often located in the deeper zones of the tumour and in some in different sites in patients with multifocal tumours. One such patient had grade 1 tumours in one calyx, grade 2 in another, and a grade 3 tumour in the renal pelvis. Areas of carcinoma in situ were found in association with and away from the tumours in 10 patients all of whom had grades 2 or 3 tumours. In two patients the neph-

Table 1 Transitional carcinoma of the upper urinary tract: histology

\begin{tabular}{|c|c|c|c|c|c|c|c|c|}
\hline & \multirow[t]{2}{*}{ Total } & \multicolumn{6}{|c|}{ Grade of tumour } & \multirow{2}{*}{$\begin{array}{l}\text { Carcinoma } \\
\text { in situ only* }\end{array}$} \\
\hline & & $l$ & 2 & 3 & 1 and 2 & 2 and 3 & 1,2 and 3 & \\
\hline $\begin{array}{l}\text { No of patients: } \\
\text { Without invasion } \\
\text { Invasion }\end{array}$ & $\begin{array}{l}54 \\
16\end{array}$ & $\begin{array}{l}17 \\
12\end{array}$ & $\begin{array}{r}19 \\
2\end{array}$ & 3 & $\begin{array}{l}8 \\
1\end{array}$ & 4 & 1 & $\begin{array}{l}2 \\
1\end{array}$ \\
\hline $\begin{array}{l}\text { Invasion } \\
\text { Lamina propria } \\
\text { Superficial muscle } \\
\text { Deep muscle } \\
\text { Kidney tubules }\end{array}$ & $\begin{array}{r}18 \\
4 \\
10 \\
5\end{array}$ & $\begin{array}{l}2 \\
3\end{array}$ & $\begin{array}{r}12 \\
3 \\
6 \\
1\end{array}$ & & $\begin{array}{l}3 \\
1 \\
3\end{array}$ & & 1 & $\begin{array}{l}1 \\
1\end{array}$ \\
\hline $\begin{array}{l}\text { Kidney and interstitial tissue } \\
\text { sometimes tubules } \\
\text { Lymphatics } \\
\text { Squamous metaplasia } \\
\text { Glandular metaplasia } \\
\text { Associated CIS }\end{array}$ & $\begin{array}{r}15 \\
17 \\
22 \\
5 \\
10\end{array}$ & $\begin{array}{l}1 \\
6 \\
1\end{array}$ & $\begin{array}{l}6 \\
8 \\
8 \\
3 \\
6\end{array}$ & $\begin{array}{l}3 \\
1 \\
2 \\
2\end{array}$ & $\begin{array}{l}3 \\
3 \\
4\end{array}$ & $\begin{array}{l}2 \\
3 \\
2 \\
1 \\
2\end{array}$ & $\begin{array}{l}1 \\
1\end{array}$ & \\
\hline
\end{tabular}

*No macroscopic tumour 
Carcinoma of the upper urinary tract

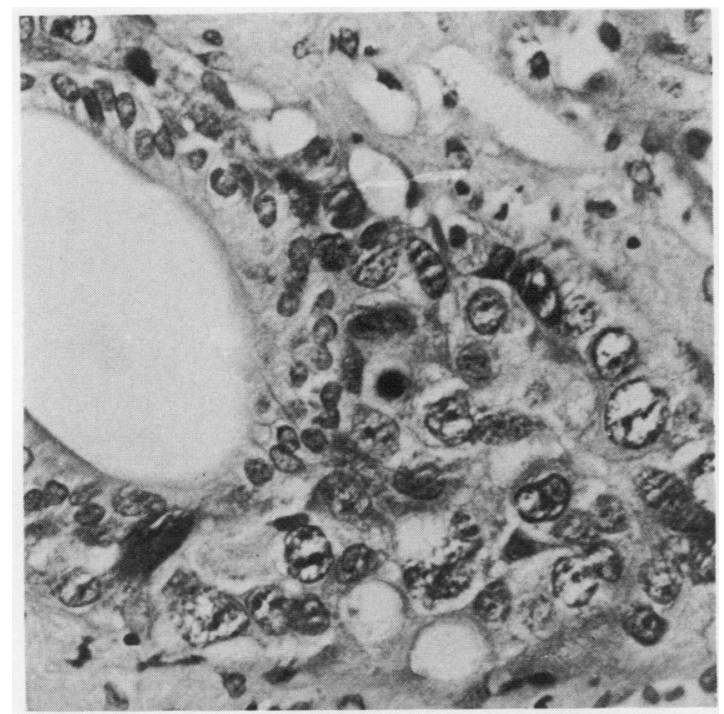

Fig. 2 Renal tubule: in situ transitional carcinoma.

(Haematoxylin and eosin.) $\times 400$.

roureterectomy specimen showed carcinoma in situ only, without a solid or papillary tumour. In one there was extensive in situ carcinoma of the renal pelvis without evidence of invasion. In the other the carcinoma in situ had spread to the lower pole calyces and the collecting tubules of the renal papillae (Fig. 2), and islands of malignant cells were found in the lamina propria of the renal pelvis. Tumours showing squamous metaplasia were found in 22 patients of whom 16 had grade 2 or 3 tumours. The higher grades

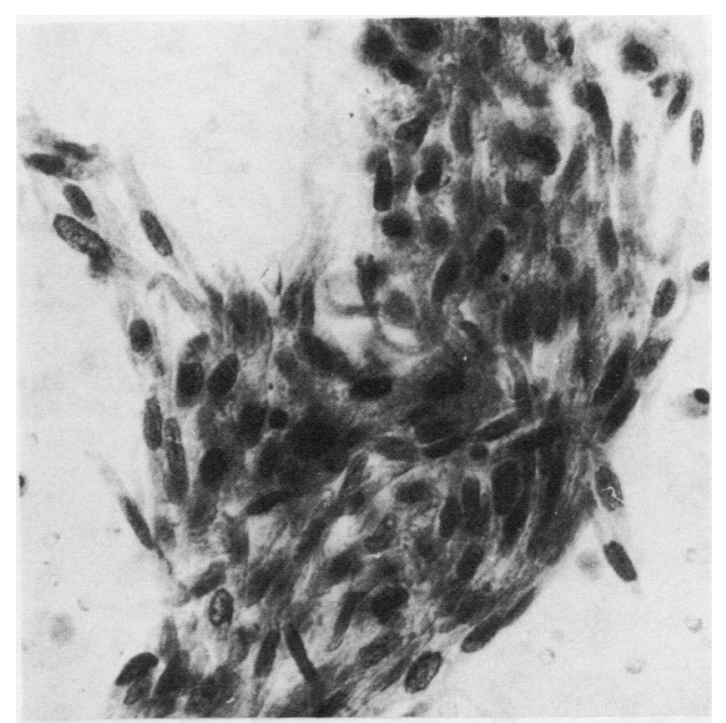

Fig. 3 Voided urine: transitional carcinoma grade 1. (Papinacolaou.) $\times 720$.

of tumours predominated in this group: $3 \bar{j}$ patients $(65 \%)$ had grade 2 or 3 tumours, or tumours with areas of grade 2 or 3 . Only 16 of the 54 patients had no evidence of invasion, and 12 of these had grade 1 tumours. All but four patients with grade 2 or 3 tumours throughout, or in deeper zones, had evidence of invasion: 10 had deep muscle invasion, 15 had invasion of the interstitial tissue of the kidney, and 17 had invasion of the lymphatics, all of which carry a poor prognosis.

Table 2 Transitional carcinoma of the upper urinary tract: cytological diagnosis

\begin{tabular}{llccc}
\hline & No patients & No positive (\%) & $\begin{array}{l}\text { No with suspected } \\
\text { tumour (\%) }\end{array}$ & No negative (\%) \\
\hline Total & 54 & $36(67)$ & $11(20)$ & $7(13)$ \\
Tumour grade 1 & 17 & $8(47)$ & $5(29 \cdot 5)$ & $4(23 \cdot 5)$ \\
Grade 2 & 19 & $15(79)$ & $2(10 \cdot 5)$ & $2(10 \cdot 5)$ \\
Grade 3 & 3 & $1(33)$ & $1(33)$ & $1(33)$ \\
Mixed grades 1, 2 and 3 & 13 & $10(77)$ & $3(23)$ & \\
Carcinoma in situ & 2 & $2(100)$ & & \\
\hline
\end{tabular}

Table 3 Transitional carcinoma of the upper urinary tract: material for cytology

\begin{tabular}{|c|c|c|c|c|}
\hline Type of specimen & No of specimens & No positive (\%) & $\begin{array}{l}\text { No with suspected } \\
\text { tumour }(\%)\end{array}$ & No negative (\%) \\
\hline $\begin{array}{l}\text { Urines: } \\
\text { Voided } \\
\text { Ileal conduit } \\
\text { Cystoscopic } \\
\text { Ureteric and pelvic }\end{array}$ & $\begin{array}{r}54 \\
15 \\
6\end{array}$ & $\begin{array}{r}38(70) \\
12(80) \\
3(50)\end{array}$ & $\begin{array}{l}6(11) \\
1(7) \\
0\end{array}$ & $\begin{array}{c}10(18 \cdot 5) \\
2(13) \\
3(50)\end{array}$ \\
\hline $\begin{array}{l}\text { urine } \\
\text { Ureteric brush } \\
\text { Aspirates: }\end{array}$ & $\begin{array}{r}22 \\
2\end{array}$ & $\begin{array}{c}12(55) \\
2(100)\end{array}$ & $\begin{array}{l}\left.8 i^{2} j\right) \\
0\end{array}$ & $\begin{array}{l}2(9) \\
0\end{array}$ \\
\hline $\begin{array}{l}\text { Antegrades } \\
\text { Intrarenal } \\
\text { Perirenal }\end{array}$ & $\begin{array}{l}4 \\
1 \\
1\end{array}$ & $\begin{array}{l}3 \\
1 \\
1\end{array}$ & 1 & 0 \\
\hline
\end{tabular}


Fig. 4 Section of transitional carcinoma grade 1:

exfoliating surface. (Haematoxylin and eosin.) $\times 400$.

\section{CYTOPATHOLOGY}

Table 2 shows the diagnostic value of preoperative urinary cytology. Sixty seven per cent of all upper tract tumours in this series were diagnosed by preoperative urinary cytology, and a further $20 \%$ were suspected. As expected the largest number of positive diagnoses was made in the higher grades of tumour. Thus $75 \%$ of the 35 patients with grade 2 or 3 tumours, or areas of grade 2 or 3 , had a positive preoperative diagnosis of tumour, and a further $17 \%$ had suspected tumour. Cytological diagnosis of tumour was most difficult in the 17 patients with grade 1 tumours with only $47 \%$ positive reports and $29.5 \%$ suspected. Of the three patients with grade 3 tumours, two had complete pelviureteric junction obstruction.

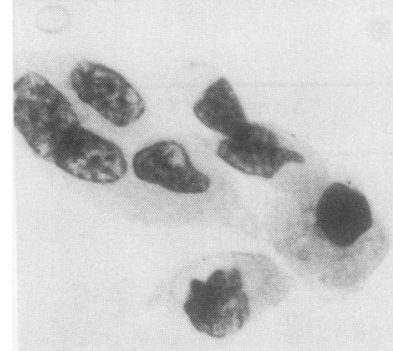

Fig. 5 Voided urine: transitional carcinoma grade 2. (Papinacolaou.) $\times 720$.

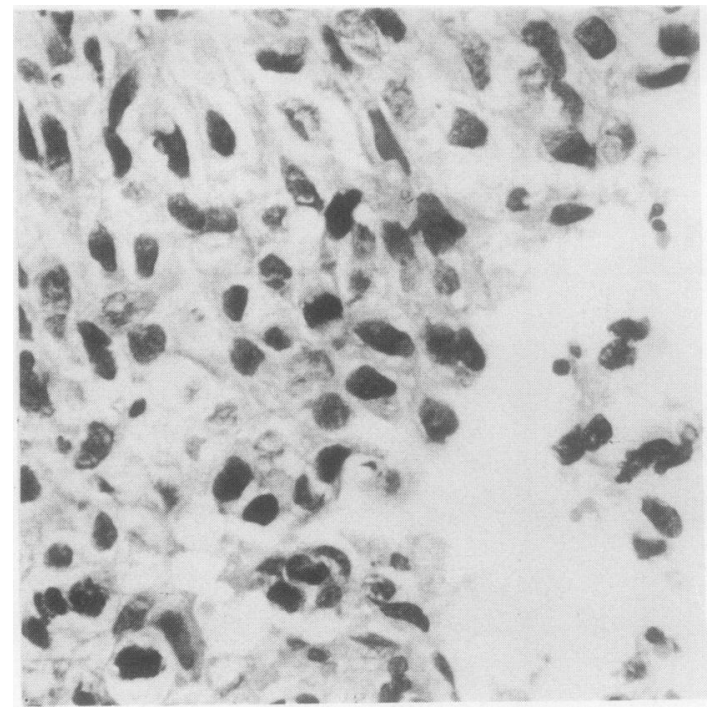

Fig. 6 Section of transitional carcinoma grade 2. (Haematoxylin and eosin.) $\times 400$.

Antegrade aspirates in one contained cells suggestive of malignancy. In the other voided urine was understandably negative and no further preoperative cytology was performed. The two patients with in situ carcinoma without macroscopic tumour had positive cytology.

Table 3 analyses the cytological findings according to the different types of material sent for diagnosis. With the exception of direct aspiration of tumour, the

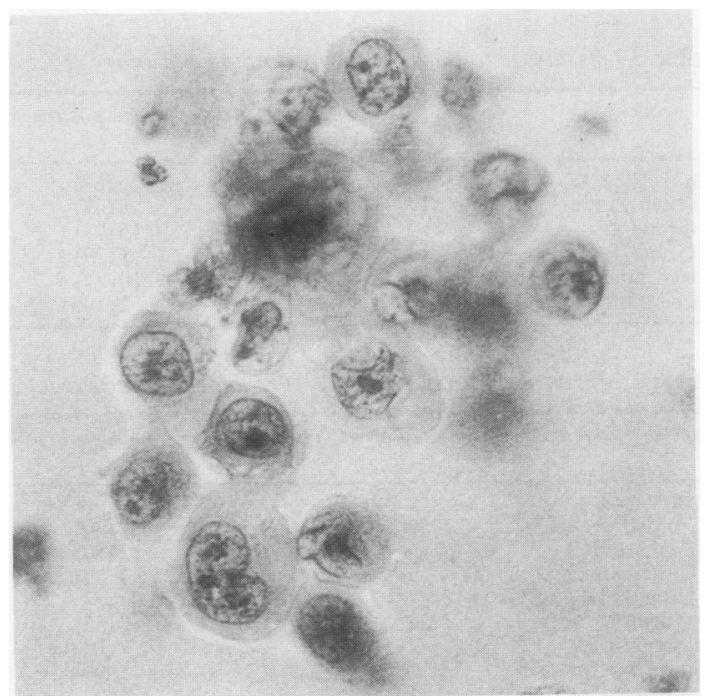

Fig. 7 Voided urine: transitional carcinoma grade 3. (Papinacolaou.) $\times 720$. 


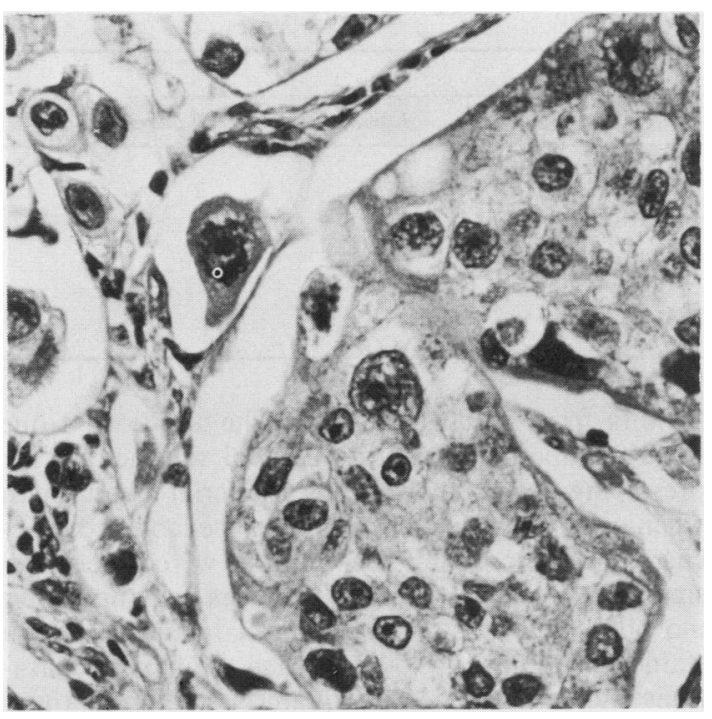

Fig. 8 Section of transitional carcinoma grade 3. (Haematoxylin and eosin.) $\times 400$.

results show that the highest yield of positive reports was found in the spontaneously voided urines with $70 \%$ of voided urines and $80 \%$ of ileal conduit urines positive for malignancy. Ileal conduit cytology was positive in seven of eight patients with total cystectomy. In six this was the only diagnostic material available. In a seventh aspiration of material from a lower calyx contained malignant cells with features similar to those in the ileal conduit urines. Fine needle

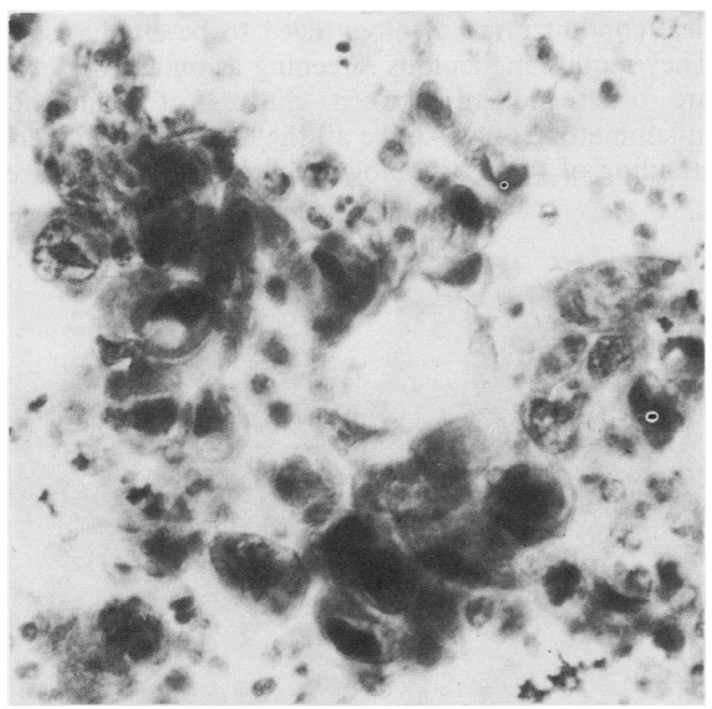

Fig. 9 Ileal conduit urine. Carcinoma in situ.

(Papinacolaou.) $\times 500$. aspiration of solid masses was used on two occasions in this series: for the diagnosis of an intrarenal mass in a patient with a history of bladder carcinoma; and in another patient to establish the diagnosis of extrarenal extension of a transitional tumour following partial nephrectomy for transitional carcinoma. In both patients there were unequivocal features of high grade transitional carcinoma.

\section{CYTOLOGICAL GRADING OF TUMOURS}

A cytological assessment of tumour grade was made by analysing the morphological features of the cells in the cytological material in 49 of the 54 patients in the series. A tumour grade was assigned according to the following criteria:

Grade 1 (Figs. 3 and 4) Included in this category were cells normal, or smaller than normal in size, and round, oval, or elongated in shape, nuclei normal in size or irregular, sometimes with notched or angular forms; chromatin that was coarsened, granular, or thread like; Nucleoli was not a feature; black structureless nuclei seen especially in single cells in the background.

Grade 2 (Figs. 5 and 6) This category comprised cells that were enlarged, round, oval, or polygonal in shape with nuclei one and a half to twice the normal size and occasional giant or multinucleate forms. $\mathrm{Nu}$ clei were generally vesicular, round, oval, or irregular in shape with prominent coarse, granular, or threadlike chromatin and a conspicuous nuclear membrane. Black structureless nuclei were common. Nucleoli were occasionally present.

Grade 3 (Figs. 7 and 8 ) There was a pattern similar to that of grade 2 but with more nuclear enlargement and cellular pleomorphism. Nucleoli and mitotic figures were more common. In all grades of tumour the malignant cells were arranged both singly and in small, or large irregular clusters. The morphology of the single cells was as important and helpful in diagnosis as that of the clusters and often more helpful in those grade 1 tumours whose features were very similar to benign and hyperplastic urothelium. Variation of nuclear size, shape, and staining within small sheets of cells was another helpful diagnostic feature. In situ carcinoma often shed cells that were arranged in flat sheets with features of high grade transitional carcinoma. This feature, however, was not sufficiently reliable to distinguish carcinoma in situ from a solid or invasive tumour (Fig. 9).

Table 4 shows the results of cytological grading and compares the cytological and histological grading. Cytological grading matched the histological grade in 12 of the 14 grade 1 tumours, 14 of the 18 grade 2 tumours, and 10 of the 13 mixed tumours with areas of grades 2 and 3. A higher grade was assigned to two grade 1 tuinours, while seven of the higher grade 
Table 4 Grading of upper tract tumours: cytology compared with histology

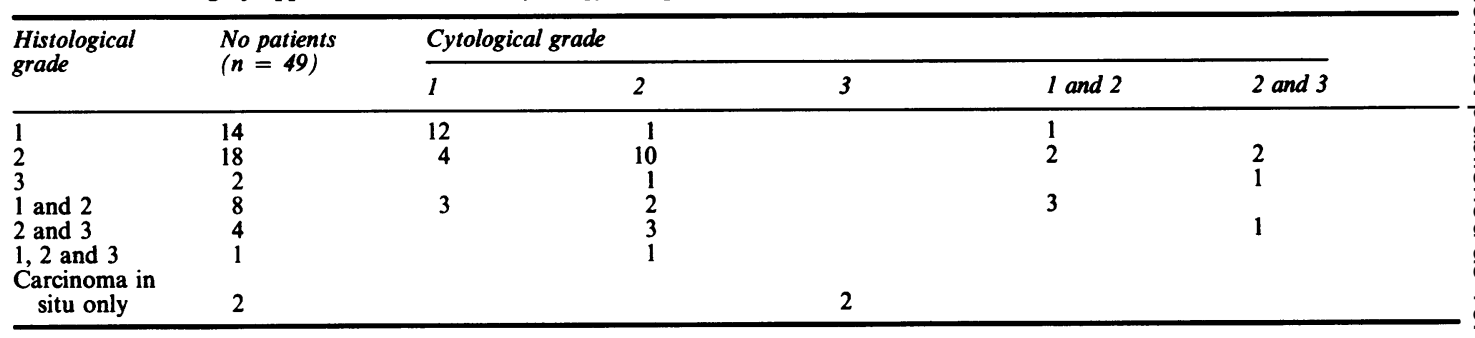

tumours were assigned grade 1 by cytology. Two cases of in situ carcinoma were assigned grade 3 on cytology.

\section{Discussion}

The efficiency of cytology in achieving a reliable diagnosis of urothelial tumour depends on close cooperation between the clinician, radiologist, and cytopathologist, as several authors have indicated. ${ }^{12}$ In the diagnosis of filling defects in the urinary tract in particular the cytopathologist must be thoroughly acquainted with the clinical and radiological picture of each patient. Likewise, the clinician and radiologist must clearly appreciate the techniques available for cytological diagnosis and their potential for success, as well as the problems associated with interpretation of the different types of material. Unlike bladder tumours where cystoscopic biopsy can be carried out, the cytological specimens may be the only source of material on which definitive diagnosis can be made before major surgery. The cytopathologist, therefore, occupies a key position in the diagnostic work up of upper tract tumours. The cytological diagnosis may largely influence the decision whether to operate as well as the nature of the operation-whether conservative or radical. ${ }^{3}$ The radiological investigation may also be influenced by the finding of malignant cells in the urine. If cytoscopy has proved negative the radiologist may plan a high contrast urogram with tomography to assist the localisation of upper tract tumour (MJ Kellett, personal communication).

In this series tumour was diagnosed preoperatively in $67 \%$ of the 54 patients. A positive report was made in $47 \%$ of the grade 1 and $75 \%$ of the tumours graded 2 or 3. The most useful material for diagnosis was voided urine collected from a well hydrated patient before instrumentation. This formed an essential baseline in all cases in which there was no obstruction to the flow of urine past the tumour. Collection of urines before instrumentation ensured that all cellular material present was spontaneously exfoliated and avoided the difficulties inherent in distinguishing sheets of traumatically detached hyperplastic epi- thelium from grade 1 tumours. The addition of one $\stackrel{\vec{\omega}}{\circ}$ third volume of $95 \%$ ethyl alcohol was helpful for preserving cells and reducing bacterial overgrowth when delays in specimens reaching the laboratory occurred. Millepore filter preparations were superior to smears both in the yield of tumours cells and their 4 morphological details. Additional Papanicolaou stained smears were of value when the filter preparations showed evidence of squamous metaplasia and keratinisation.

The value of ileal conduit urines in the diagnosis of $\stackrel{\rho}{\mathcal{}}$ transitional carcinoma of the upper urinary tract has $\overrightarrow{0}$ not been fully appreciated. In the present series upper tract tumours were diagnosed in six of seven patients who had undergone cystectomy. Wolinska and Melamed $^{4}$ described the cytological features in ileal urines in a series of 115 patients. Of the 11 with a positive diagnosis of tumour, five had a new primary transitional tumour of the upper tract. They stated that periodic ileal conduit urine cytology offers the best means of early detection of upper tract tumours in patients who have had cystectomy. The problems of ileal conduit urine cytology need to be emphasised. They require meticulous screening as malignant cells are often hidden between clusters of ileal and inflammatory cells. Above all they require an understanding of the morphology of ileal cells, which are

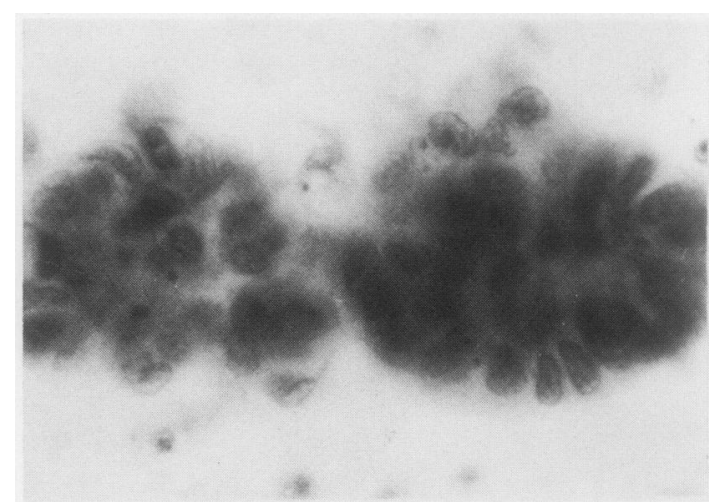

Fig. 10 Papillary cluster of ileal cells. (Papinacolaou.) $\times 720$. 
almost invariably present in abundance both singly and in clusters. These clusters are often rounded or papillary in shape and must be distinguished from similarly shaped groups of low grade transitional carcinoma with which they may be confused.

Clusters of ileal cells are characterised by smooth borders and thinly textured cytoplasm, in which an occasional goblet cell may be seen (Fig. 10). Their nuclei, although often irregular in shape, are usually smaller than transitional cell nuclei and have a fine granular chromatin. Clusters of differentiated transitional carcinoma in contrast have thicker textured deeper pink cytoplasm and larger nuclei with a coarse granular or thread like chromatin. There is no likelihood of confusing the higher grades of transitional carcinoma with clusters of ileal cells. The single ileal cells in the background have similar features to those in the clusters but are usually more degenerate with small pinpoint pyknotic nuclei or larger "emptylooking" nuclei. A transition may be seen between the single ileal cells in the background and the papillary clusters of ileal cells.

Ureteric and pelvic urines taken during retrograde cystoscopy and brushings of abnormal areas followed by saline washings provide an additional source of diagnostic material, as do urines aspirated from an abnormal calyx or from the pelvis in patients with obstruction of pelviureteric junction. Gill ${ }^{5}$ reported no false positive or negative diagnoses on brush cytology in over 40 patients with upper tract filling defects. As with all material collected by instrumentation the cytopathologist needs to be familiar with the problem of distinguishing tumours from sheets of hyperplastic or atypical traumatically detached benign epithelium, thereby avoiding false positive reports. Thus, although there is no difficulty in accurately diagnosing the higher grades of tumour in these instrumentation specimens, it can be very difficult, if not impossible, to diagnose a grade 1 tumour in this type of material. In this instance the voided urines provide invaluable supportive information. Histological sections of tissue fragments or blood clot may contain small sheets of tumour with diagnostic features.

The grading of transitional tumours is a difficult area in both histology and cytology. The criteria for histological grading of transitional tumours have been clearly defined, but the application of these criteria remains subjective and even in the best hands liable to inconsistencies. Ooms ${ }^{6}$ in an objective study on the grading of 57 TUR specimens of transitional carcinoma of the bladder, using the WHO grading system, found a disturbingly high incidence of inconsistencies in grading between and within subjects. He went so far as to suggest that these inconsistencies might invalidate the usefulness of transitional tumour grading in clinical decision making.

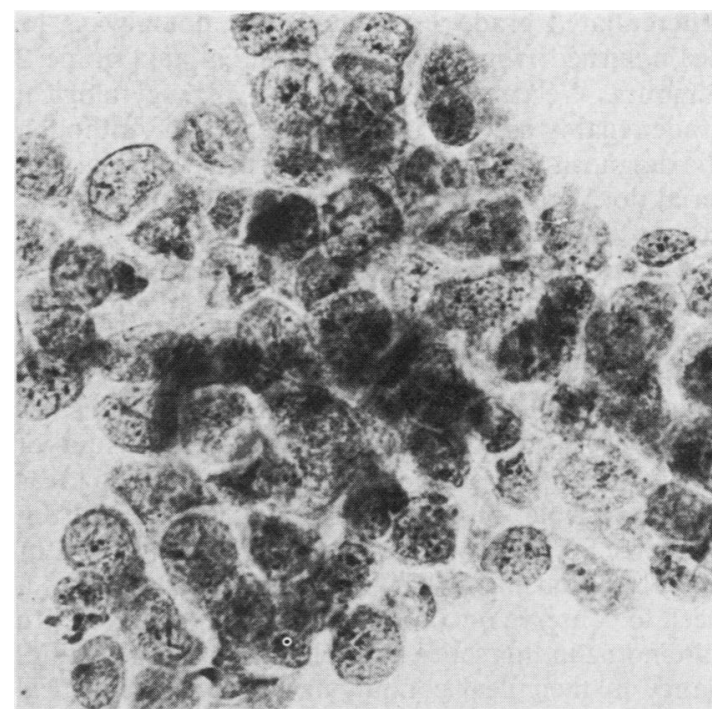

Fig. 11 Brush cytology. Grade 2 transitional carcinoma. (Papinacolaou.) $\times 450$.

The fact that the tumours, whether localised or multifocal, may not be of uniform histological grade throughout creates an additional problem for the cytologist. Variability of tumour grade was noted in 13 of the patients in this series. The areas of higher grade were often in the deeper zones of the tumour with the exfoliated cells being derived from the better differentiated superficial areas. A cytological assessment of tumour grade correlated with the histological grade in 12 of 14 grade 1 tumours. All but seven of the 35 cases of tumours of grades 2 or 3 were assigned to the higher grades by cytology. Of the seven assigned grade 1 by cytology, four were grade 2 tumours and three mixed grades 1 and 2 with the higher grade areas located in the deeper zones of the tumour.

The grading of transitional tumours in cytological material is no longer an academic exercise. Karlsen ${ }^{3}$ cited several papers indicating that prognosis in upper tract tumours relates to the grade and stage of malignancy and not to the extent of the surgical procedure. This, together with the fact that $10 \%$ of patients have bilateral upper tract tumours, supports the need for conservative surgery and segmental resection of low grade non-invasive tumours. The choice of surgical procedure demands a reliable preoperative diagnosis and assessment of tumour grade by urine cytology and confirmation, when appropriate, by brush cytology. ${ }^{3}$ There are several published reports on the grading of transitional tumours in cytological material. ${ }^{178}$ The findings in this study agree with that of Murphy ${ }^{1}$ - that low grade tumours can be reliably distinguished from those of high grade transitional tumours in cytological material, but that the less well 
differentiated grade 1 tumours may not always be distinguished from the better differentiated grade 2 tumours. We can conclude that a high cytological grade reliably predicts a high grade tumour, although the diagnosis of low grade tumour in cytological material does not exclude a higher grade tumour in the deeper non-exfoliating areas.

Malignant cells from areas of flat in situ carcinoma have the cytological features of high grade tumours. The features found in this and other studies ${ }^{1}$ do not differentiate them from invasive carcinomas. The localisation of the source of the cells is of obvious importance. On the one hand, the invasive potential of in situ carcinoma demands resection of affected areas where possible; on the other hand, it is clearly undesirable for nephroureterectomy to be performed for a process that may be bilateral and where there is a need to conserve renal tissue. Both cases of flat in situ carcinoma in this series had cells of high grade malignancy in their ileal conduit urines and radiological abnormalities on the intravenous urogram. Antegrade aspiration of material from an abnormal calyx confirmed the source of the malignant cells in the patient with microscopic invasion. Her ileal conduit urine became positive within three months of nephroureterectomy. Antegrade aspirate showed high grade malignant cells and biopsy confirmed a grade 3 transitional carcinoma invading medullary tubules and parenchyma of the remaining kidney.

Cytological diagnosis must be reliable if it is to make a useful contribution to the diagnosis of filling defect in the upper urinary tract. The question of false positive diagnosis cannot be assessed in this series of patients all of whom had upper tract tumours. As the literature indicates, however, ${ }^{12910}$ it is essential that patients with persistent positive cytology and negative findings on full investigation are carefully followed up. One of the patients in this series had persistent positive cytology for six months before bilateral ureteric urines and further radiological studies localised an abnormality in the middle calyx. Nephroureterectomy showed a grade 2 transitional carcinoma with extensive spread to the renal parenchyma from which the patient died six months later. One of the most important causes of true false positive urinary cytology published is calculi in the upper tract. Rubben ${ }^{11}$ in a series of 120 patients with stones in the upper urinary tract reported $5 \%$ positive and $4 \%$ suspected of malignancy. He highlighted the reliability of urine cytology in patients with filling defects in the upper urinary tract when the findings indicated a high grade tumour, but calculi should be excluded when making an unequivocal diagnosis of a low grade tumour as the cause of an upper tract filling defect. In a study of urine cytology in 135 patients with calculi in the St Peter's Hospitals 7\% had cells with features suggestive of low grade tumour. ${ }^{12}$ None of these patients was found to have tumours at the time or on follow up. In patients known to have calculi the cytologist should therefore be wary of making a diagnosis of low grade tumour. On the other hand, the finding of cells with features of grades 2 and 3 transitional carcinoma should justify a confident positive report even in the presence of calculi.

There needs to be a greater awareness among urologists of the contribution to early diagnosis of upper tract tumours that a centre experienced in urinary cytopathology can make. One patient in this series was referred after six months of investigation including laparotomy for a filling defect in mid ureter. Urine cytology was not performed until referral. Voided urine, together with ureteric brushings (Fig. 11), showed grade 2 transitional carcinoma, which was confirmed by ureterectomy by which time deep muscle and lymphatics had been invaded. There is little doubt that urine cytology would have shown the diagnosis at the outset in this patient.

Of the 54 patients in this series, there were only 16 without evidence of invasion of whom 12 had grade 1 tumours. Sixty five per cent of the patients had grade 2 or 3 tumours and these were the patients with the most advanced disease at the time of surgery with deep muscle invasion, infiltration of the interstitial tissue of the kidney, and lymphatic invasion, all of which indicated a poor prognosis. ${ }^{13}$ It was in this group of patients with the higher grade tumours that cytology was most helpful with a preoperative diagnosis of tumour in $75 \%$. Provided that cytological examination is made by those experienced in all aspects of urinary cytology, it has an important contribution to make to the diagnosis of transitional carcinoma of the upper urinary tract.

I thank my histopathology, clinical, and radiology colleagues for use of the material: Mr Manmeet Singh for two of the cases; and Miss Pat Gunter for photographic help.

\section{References}

${ }^{1}$ Murphy WM, Soloway MS, Jokkola AF, Crabtree WN, Ford KS. Urinary cytology and bladder cancer. The cellular features of transitional neoplasms. Cancer 1984;53:1555-65.

${ }^{2}$ Nelson RP. New concepts in staging and follow-up of bladder carcinoma. Urology 1983;21:105-22.

${ }^{3} \mathrm{Karlsen} \mathrm{S}$. Improved technique for retrograde brushing in diagnosis of urothelial tumours of upper urinary tract. Urology 1981; 18:345-8.

${ }^{4}$ Wolinska WH, Melamed MR. Urinary conduit cytology. Cancer 1973;32:1000-6.

${ }^{5}$ Gill WB, Bibbo M, Thompson S, Lu CT. Evaluation of renal masses including retrograde brushing. Surg Clin North Am 1976;56:149-74.

${ }^{6}$ Ooms ECM, Anderson WAD, Alons CL, Boon ME, Veldhuisen $\mathrm{RW}$. Analysis of the performance of pathologists in the grading

(n)

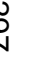

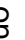

.
梦 
of bladder tumours. Hum Pathol 1983;14:140-3.

${ }^{7}$ King EB. Cytology of bladder cancer. In: Bryan GT, Cohen EM, eds. The pathology of bladder cancer. Vol 1. Florida: CRC Press, 1983:91-151.

${ }^{8}$ Esposti PL, Zajicek J. Grading of transitional cell neoplasms of the urinary bladder from smears of bladder washings. Acta Cytol 1972;16:529-37.

${ }^{9}$ Lewis RW, Jackson JR, Murphy WM, Leblanc GA, Meehan WL. Cytology in the diagnosis and follow-up of transitional cell carcinoma of the urothelium: A review with a case series. J Urol 1976;116:43-6.

${ }^{10}$ Heney NM, Szyfelbein WM, Daly JJ, Prout GR, Bredin HC. Positive urinary cytology in patients without evident tumour. $J$
Urol 1977;117:223-4.

${ }^{11}$ Rubben HF, Hering F, Dahm HH, Lutzeyer W. Value of exfoliative urinary cytology for differentiation between uric acid stone and tumour of upper urinary tract. Urology 1982;20:571-3.

${ }^{12}$ Highman W, Wilson E. Urine cytology in patients with calculi. $J$ Clin Pathol 1982;35:350-6.

${ }^{13}$ Booth CM, Cameron KM, Pugh RCB. Urothelial carcinoma of the kidney and ureter. Br J Urol 1980;52:430-5.

Requests for reprints to: Dr Wilma J Highman, Department of Pathology, St Paul's Hospital, Endell Street, London WC2H 9AE, England.

\section{The February 1986 issue}

\section{THE FEBRUARY 1986 ISSUE CONTAINS THE FOLLOWING PAPERS}

Aplastic and hypoplastic episodes in sickle cell disease and thalassaemia intermedia ALISON I BROWNELL, DA MCSWIGGAN, WD CUBITT, MJ ANDERSON

Idiopathic haemochromatosis and HLA antigens in Italy: Is A3 Bw35 HLA haplotype a marker for idiopathic haemochromatosis gene in north east regions? A PIPERNO, S FARGION, N PANAIOTOPOULOS, E DEL NINNO, MT TADDEI, G FIORELLI

Platelet volume analysis in the differential diagnosis of thrombocytosis J VAN DER LELIE,

AEG KR VON DEM BORNE

Marrow involvement in $\mathrm{T}$ cell lymphoma initially presenting as abnormal myelopoiesis MJ AUGER, JRG NASH, MJ MACKIE

Laminin and fibronectin in adenoid cystic carcinoma AJ d'ARDENNE, P KIRKPATRICK, CA WELLS, JD DAVIES

Cyclosporin and renal graft histology AJ d'ARDENNE, MS DUNNILL, JF THOMPSON, D MCWHINNIE, RFM WOOD, PJ MORRIS

Morphological differentiation between rejection and cyclosporin nephrotoxicity in renal allografts

GH NEILD, DH TAUBE, RB HARTLEY, L BIGNARDI, IS CAMERON, DG WILLIAMS, CSOGG, CJ RUDGE

Lupus nephritis: clinicopathological study of 162 cases in Thailand P PARICHATIKANOND, ND FRANCIS, P MALASIT, T LAOHAPAND, S NIMMANNIT, L SINGCHOOVONG, S NILWARANGKUR, P CHRIRAWONG, S VANICHAKARN

Membranous glomerulonephritis DJ HARRISON, D THOMSON, MARY K MACDONALD

Coconut matting bezoar identified by a combined analytical approach DA LEVISON, PR CROCKER, TA BOXALL, KJ RANDALL

Early cellular responses to intradermal injection of Kveim suspension in normal subjects and those with sarcoidosis CS MUNRO, DN MITCHELL, LW POULTER, PJ COLE

Benign hepatic tumours and tumour like conditions in men PJ KARHUNEN

Proposed alternative terminology and

subclassification of so called "dysplastic naevi"
MORAG M SEYWRIGHT, VALERIE R DOHERTY, RONA M MacKIE

Deficiency of serum "pregnancy-associated" $\alpha_{2}$-glycoprotein $\left(\alpha_{2}\right.$-PAG): association with disease CHW HORNE, LINDA M GERRIE, SYLVIA S ARMSTRONG, PW BRUNT, NAG MOWAT, TS SINCLAIR

Dihydropteridine reductase activity in dried blood spots: effects of aging and senile dementia of the Alzheimer type CATHERINE M JEEPS, ANNE SILCOX, BARBARA LLOYD, BARBARA E CLAYTON

Role of toxoplasmosis in the aetiology of some cardiac diseases: an immunobiological investigation D ŠIBALIĆ, O DJURKOVIĆ-DJAKOVIĆ

Rapid diagnosis of Gram negative urinary infections: identification and antimicrobial susceptibility testing in 24 hours CATHERINE M DUPEYRON, GEORGIE A GUILLEMIN, GJ LELUAN

Latex particle agglutination for detecting and identifying Clostridium difficile RABOWMAN, SUZAN A ARROW, TV RILEY

Clinical importance of Campylobacter pyloridis and associated serum IgG and IgA antibody responses in patients undergoing upper gastrointestinal endoscopy LINDA BOOTH, G HOLDSTOCK, H MaCBRIDE, P HAWTIN, JR GIBSON, A IRELAND, J BAMFORTH, CLAIRE E DUBOULAY, RS LLOYD, AD PEARSON

Inhibition of Pseudomonas aeruginosa from cystic fibrosis by selective media K FONSECA, JANE MaCDOUGALL, TL PITT

Detection of group B streptococcal antigen in necropsy specimens using monoclonal antibody and immunoperoxidase staining RG FELDMAN, SM LAW, JR SALISBURY

\section{Technical method}

Sensitive and rapid measurement of fibrin polymerisation by laser nephelometry A RUIZ-ARGUELLES, BEATRIZ PEREZ-ROMANO

\section{Letters to the Editor}

Book reviews 